\title{
Electrophysiological Patterns of Diabetic Polyneuropathy: Experience from a Tertiary Care Hospital of Bangladesh
}

\author{
Islam MR ${ }^{\mathrm{a}}$, Rahman $\mathrm{T}^{\mathrm{b}}$, Habib R ${ }^{\mathrm{c}}$, Irfan $\mathrm{SMR}^{\mathrm{d}}$, Rahman $\mathrm{A}^{\mathrm{e}}$, Bhowmik NB ${ }^{\mathrm{f}}$, Haque MA ${ }^{\mathrm{g}}$
}

\begin{abstract}
Background: Complications of diabetes mellitus (DM) represent the major cause of morbidity and mortality in the modern era, diabetic polyneuropathy (DPN) being one of the most frequents. Nerve conduction study is employed to detect neuropathy. This study is done to see the electrophysiological pattern of diabetic polyneuropathy in a tertiary care setting.

Methods: Study was carried out in 100 diagnosed DM patients attending department of neurology, BIRDEM General Hospital from July, 2015 to June, 2016. Diabetic patients with good glycaemic control were grouped in group A and that with poor glycaemic control in group B. Clinical questionnaire and neurological examination were administered, and nerve conduction study (NCS) were performed using standard techniques.

Results: Among the 100 patients studied, 54 (54\%) patients were Male and 46 (46\%) patients were Female. $39 \%$ patients who had normal HbAlC was designated as group A and $61 \%$ patients having high HbAlc was designated as group B. Mean age of patients in group A was $55.02 \pm 10.45$ years and group B was $54.94 \pm 11.13$ years. Mean duration of diabetes in group $A$ was $10.49 \pm 4.43$ years and group B was 12.44 \pm 5.14 years. Alterations in NCS included lowered amplitudes and slowed conduction velocities. Most common axonal pattern was found in peroneal nerves and most common demyelinating pattern was found in sural nerves. Sensory conduction velocity in significantly reduced in all sensory nerves in group B in comparison to group A. Compound motor action potential (CMAP) is significantly reduced on peroneal nerve in group $B$.

Conclusion: Risk of neuronal involvement is increased as Diabetes mellitus progresses further which can be accelerated by poor glycaemic control. NCS is used to as an important tool to diagnose the peripheral neuropathy. Early diagnosis of neuropathy can be done by routine NCS and complications of neuropathy can be prevented by controlling Diabetes mellitus more meticulously.
\end{abstract}

Keywords: Diabetes mellitus, nerve conduction studies, diabetic Neuropathy

(BIRDEM Med J 2017; 7(2): 114-120)

\section{Author Information}

a. Dr. Md. Rashedul Islam, MBBS, MRCP (UK), FCPS (Medicine), FACP(USA), Junior Consultant, Department of Neurology, BIRDEM General Hospital.

b. Dr. Tanbin Rahman, MBBS, MRCP(UK), Registrar, Medicine, Green life Medical College \& Hospital

c. Dr. Rumana Habib, MBBS, FCPS (Medicine), Assistant Professor, Department of Neurology, BIRDEM G eneral Hospital

d. Dr. S. M. Rezaul Irfan, FCPS(Medicine), Registrar, Cardiology, BIRDEM General Hospital

e. Dr. Aminur Rahman, MD, FACP(USA), MBBS, Consultant, Department of Neurology, BIRDEM General Hospital

f. Prof. Nirmalendu Bikash Bhowmik, MBBS, MD, Professor, Department of Neurology, BIRDEM General Hospital

g. Prof. Dr. Md. Amirul Haque, MBBS, FCPS, DCN, FACP(USA), FRCP, Professor \& Head, Department of Neurology, BIRDEM General Hospital

Address of correspondence: Dr. Md Rashedul Islam, Junior Consultant, Department of Neurology (Room No-1423, 13 ${ }^{\text {Th }}$ Floor), BIRDEM General Hospital, Shahbag, Dhaka-1000, Email: rashed 2k2001@yahoo.com

Received: July 20, 2016

Accepted: February 28, 2017

\section{Introduction}

Diabetic peripheral neuropathy (DPN) is common, affecting up to $50 \%$ of patients, ${ }^{1}$ and predisposes patients to severe functional limitations through symptoms of unremitting pain and unsteadiness. Its complications such as foot ulceration and amputation ${ }^{2}$, 3 are associated with substantial health care costs, socioeconomic consequences including loss of work time, ${ }^{4}$ and reduced quality of life. ${ }^{5}$ The prevalence of peripheral neuropathy in diabetic subjects approaches $70 \% .^{6}$ The presence of an abnormality of nerve conduction study and a symptom or symptoms or a sign or signs of neuropathy confirm diabetic sensorimotor polyneuropathy ${ }^{7}$.The fully expressed syndrome of DPN is a symmetrical distal lower-limb sensorimotor polyneuropathy. Almost without exception, sensorimotor involvement is restricted to the distal extremities of the lower limbs. By contrast, 
electrophysiological abnormalities can be found diffusely, even in nerves not affected clinically. As diabetic polyneuropathy is of insidious onset and often present at the time of diagnosis of type 2 DM, electrophysiological studies may be abnormal in diabetics even if they do not have any neuropathic symptoms ${ }^{8}$.

This study presents findings of motor and sensory nerve conduction studies (NCS) performed on diabetic patients. It is designed to observe the effects of duration of DM and glycemic control on electrophysiological study of peripheral nerves that may help in the better management of patients suffering from DPN.

\section{Methods}

This study was carried out at Department of Neurology, BIRDEM General Hospital. Diabetic patients, admitted in neurology and departments of neurology BIRDEM and referred from OPD who underwent nerve conduction study were consecutively and purposively selected from July, 2015 to June, 2016. 100 diabetic patients were selected on basis of the following criteria: (1) Diabetes mellitus patients with complaints of tingling, numbness and burning sensations in the limbs, (2) FBS $>110 \mathrm{mg} / \mathrm{dL}$, (3) History of type $2 \mathrm{DM}$ for more than 5 years.

A detailed questionnaire was filled out for each case, with a view to detecting symptoms and signs of peripheral nerve disease, excluding confounding factors that may affect NCS results, and recording complications of diabetes mellitus. Exclusion criteria included age below 18 years; asymmetric paresthesiae, sensory impairment or weakness in the lower extremities (other than that attributable to DPN); patients with any cause of neuropathy other than diabetes (including carpal tunnel syndrome, spine disease, alcoholism, liver or renal disease, toxin exposure, other endocrine metabolic or nutritional disorders, inflammatory diseases, trauma); pregnancy, patients with DM of specific aetiology and those with diabetic emergencies. Their detailed family history, treatment and medical history was taken with physical and clinical examination. Neurological examination was carried out by one examiner on all patients, focusing specifically on sensory complaints and objective abnormalities in the upper and lower extremities. Glycosylated haemoglobin ( $\mathrm{HbAlc})$ and fasting and postprandial blood sugar levels were measured in venous blood in all patients.
NCS was performed by a single investigator with standard surface stimulation and recording techniques on a Neuropack S1 four channel electromyograph with standard filter settings and a surface stimulator using a $0.1 \mathrm{~ms}$ square-wave pulse.

Measures in Diabetic peripheral Neuropathy (DPN) were employed to evaluate peroneal and tibial motor, median and ulnar motor and sensory, and sural sensory responses. Standard recording sites and stimulation to recording electrode distances were used: stimulation at the wrist and elbow for median and ulnar motor NCS recording from the abductor pollicis brevis and abductor digiti minimi respectively; stimulation at the wrist for median and ulnar antidromic sensory studies recording from the second and fifth digits respectively; stimulation at the ankle and fibular neck for peroneal motor NCS recording from the extensor digitorum brevis; and stimulation in the calf recording from the foot for sural studies. For motor NCS gain was kept at $2 \mathrm{mV} /$ division, time sweep at $2 \mathrm{~ms} /$ division, and low and high frequency filters at 10 and $32 \mathrm{kHz}$ respectively, while for sensory studies gain was at $20 \mathrm{iV} /$ division and time sweep at 1 $\mathrm{ms} /$ division, with the same filter settings. Since the studies were performed in a tropical country where the ambient temperature at the time of performing NCS was always $25^{\circ} \mathrm{C}$, limb temperature was not monitored. Compound muscle action potential amplitudes were measured from the baseline to negative peak, and onset latencies were measured for distal and proximal stimulation sites. Sensory nerve action potential (SNAP) amplitude was measured from the initial positive peak to the negative peak or from the baseline to the negative peak if there was no initial positive peak. The results were calculated on the basis of average of ten or more responses.

Conduction velocities were calculated from the onset latency and distance measurements. Motor conduction velocities were determined for the median nerve, ulnar nerve, and peroneal nerves and calculated by dividing the distance between proximal and distal stimulating cathodes by the latency. Sensory conduction velocity was calculated by dividing the distance between stimulating and recording electrodes by response latency.

All data were entered in a database, and this was exported to a statistical software (SPSS Inc, version 20) 
for analysis. Descriptive statistics such as mean, standard deviation, frequency, median, range and percentage were used to express data. Categorical variables were analysed using chi square test, while one-way analysis of variance and univariate analysis of variance were used for continuous variables. Logistic regression was employed to describe risk. A p value d" 0.05 was considered statistically significant.

\section{Results}

One hundred adult patients fulfilling the inclusion and exclusion criteria were included in this study in a period of 6 months. Standard electrophysiological studies were done to diagnose demyelinating, axonal or mixed pattern. 54 (54\%) patients were Male and 46 (46\%) patients were Female. Patients were grouped into those with $\mathrm{HbA} 1 \mathrm{ce} " 7 \%$ and those with $\mathrm{HbAlc}<7 \%$ and the groups were compared to search for effects of chronic hyperglycemia on the different variables or vice versa. 39 patients who had $\mathrm{HbA} 1 \mathrm{C}<7 \%$ was designated as group $\mathrm{A}$ and 61 patients having $\mathrm{HbA1c}>7 \%$ was designated as group B. Mean age of patients in group A was $(55.02 \pm 10.45)$ years \& group B was $(54.94 \pm 11.13)$ years. Mean duration of diabetes in group A was $(10.49 \pm 4.43)$ years \& group B was $(12.44 \pm 5.14)$ years. On electrophysiological study, most common axonal pattern was found in peroneal nerves \& most common demyelinating pattern was found in sural nerves. Motor conduction velocity was found to be significantly reduced on peroneal nerves. Sensory conduction velocity was significantly reduced in all sensory nerves in group B in comparison to group A. Compound motor action potential (CMAP) was significantly reduced in peroneal nerves in group B. No significant difference was seen in other motor nerves between two groups.

Table I. Demographic and baseline characteristics of the study subjects

\begin{tabular}{lccc} 
Parameters & $\begin{array}{c}\text { Group A: DM with normal } \\
\text { HbAlc }(\mathrm{n}=39)\end{array}$ & $\begin{array}{c}\text { Group B: DM with high } \\
\text { HbA1c }(\mathrm{n}=61)\end{array}$ & $\begin{array}{c}\text { Palue } \\
\text { Valu }\end{array}$ \\
\hline FPG (mmol/dl) & $5.18 \pm 1.51$ & $9.81 \pm 2.41$ & 0.09 \\
2h after Breakfast(mmol/dl) & $7.89 \pm 2.20$ & $12.35 \pm 3.25$ & 0.12 \\
HbAlc (\%) & $5.89 \pm 1.20$ & $10.49 \pm 1.50$ & 0.001 \\
Serum Creatnine(mg/dl) & $1.12 \pm .24$ & $1.07 \pm .31$ & 0.208 \\
Serum Urea(mg/dl) & $19.62 \pm 7.55$ & $22.90 \pm 7.37$ & 0.382 \\
TSH(mIU/L) & $2.63 \pm 1.16$ & $3.00 \pm 1.55$ & 0.959 \\
ESR(mm in 1st hour) & $20.24 \pm 11.63$ & $29.78 \pm 16.04$ & 0.085 \\
Hb\% & $13.06 \pm 1.76$ & $11.83 \pm 1.56$ & 0.170 \\
Age (Yrs) & $55.02 \pm 10.45$ & $54.94 \pm 11.13$ & 0.478 \\
Duration of DM (Yrs) & $10.49 \pm 4.43$ & $12.44 \pm 5.14$ & 0.533 \\
\hline
\end{tabular}

Table II. Percentage Distribution of axonal pattern

\begin{tabular}{lccc} 
& Normal $(\%)$ & Abnormal $(\%)$ & Total $(\%)$ \\
\hline Upper Limb CMAP & 19 & 47.75 & 66.75 \\
Upper Limb SNAP & 15 & 28 & 43 \\
Lower Limb CMAP & 24 & 30 & 54 \\
Lower Limb SNAP & 37.5 & 6 & 43.5 \\
\hline
\end{tabular}

[CMAP: Compound muscle action potential, SNAP: Sensory nerve action potential]

Table III. Percentage Distribution of demyelinating pattern

\begin{tabular}{lccc} 
& Normal $(\%)$ & Abnormal $(\%)$ & Total $(\%)$ \\
\hline Upper Limb MCV & 24.5 & 20.5 & 45 \\
Upper Limb SCV & 2.66 & 41.25 & 43.91 \\
Lower Limb MCV & 17.75 & 36.25 & 54 \\
Lower Limb SCV & 7 & 68 & 75 \\
\hline
\end{tabular}

[MCV: Motor conduction velocity, SCV: Sensory conduction velocity] 
Table IV. Electrophysiological Demyelinating pattern of upper and lower limb nerves in group A \& B

\begin{tabular}{|c|c|c|c|}
\hline Studied nerves & $\begin{array}{c}\text { Group A: DM with normal } \\
\qquad \begin{array}{c}\text { HbA1c }(\mathrm{n}=39) \\
\text { Conduction } \\
\text { velocity }(\mathrm{m} / \mathrm{S})\end{array}\end{array}$ & $\begin{array}{l}\text { Group B: DM with high } \\
\text { HbA1c }(\mathrm{n}=61) \\
\text { Conduction } \\
\text { velocity }(\mathrm{m} / \mathrm{S})\end{array}$ & P Value \\
\hline Median motor & $58.34 \pm 2.7$ & $53.73 \pm 3.7$ & 0.09 \\
\hline Ulnar motor & $53.23 \pm 2.2$ & $51.12 \pm 2.3$ & 0.08 \\
\hline Peroneal nerve & $50.6 \pm 2.7$ & $26.33 \pm 2.4$ & $0.0003 *$ \\
\hline Tibial nerve & $53.5 \pm 3.8$ & $45.2 \pm 2.2$ & 0.09 \\
\hline Sural nerve & $53.32 \pm 3.3$ & $42.35 \pm 2.4$ & $0.002 *$ \\
\hline Median sensory & $53.61 \pm 3.8$ & $31.51 \pm 2.7$ & $0.001 *$ \\
\hline Ulnar sensory & $52.3 \pm 2.7$ & $41.7 \pm 1.7$ & 0.01 \\
\hline
\end{tabular}

*Significant

Table V. Electrophysiological Axonal pattern of motor nerves

\begin{tabular}{|c|c|c|c|}
\hline \multirow[t]{2}{*}{ Studied nerves } & $\begin{array}{c}\text { Group A: DM with normal } \\
\text { HbA1c }(n=39)\end{array}$ & $\begin{array}{l}\text { Group B: DM with high } \\
\qquad \text { HbA1c }(n=61)\end{array}$ & P Value \\
\hline & CMAP, (mV) & CMAP, (mV) & \\
\hline Median motor & $10.6 \pm 2.1$ & $8.2 \pm 1.3$ & 0.08 \\
\hline Ulnar motor & $13.3 \pm 1.7$ & $11.04 \pm 1.2$ & 0.06 \\
\hline Peroneal nerve & $5.1 \pm 0.9$ & $2.44 \pm 0.6$ & $0.02 *$ \\
\hline Tibial nerve & $8.2 \pm 1.1$ & $5.8 \pm 1.22$ & 0.09 \\
\hline
\end{tabular}

*Significant

Table VI. Electrophysiological Axonal pattern of sensory nerves

\begin{tabular}{lccc} 
Studied nerves & $\begin{array}{c}\text { Group A: DM with normal } \\
\text { HbA1c }(\mathrm{n}=39)\end{array}$ & $\begin{array}{c}\text { Group B: DM with high } \\
\text { Sensory nerve action } \\
\text { potential(SNAP), }(\mu \mathrm{V})\end{array}$ & $\begin{array}{c}\text { PbA1c }(\mathrm{n}=61) \\
\text { pensory nerve action }\end{array}$ \\
\hline Median sensory & $6.3 \pm 2.3$ & $4.31 \pm 1.7$ & $0.02^{*}$ \\
Ulnar sensory & $6.5 \pm 1.6$ & $5.21 \pm 1.7$ & $0.03^{*}$ \\
Sural nerve & $10.41 \pm 4.7$ & $5.62 \pm 3.1$ & $0.001^{*}$ \\
\hline
\end{tabular}

*Significant 


\section{Graphical representation of results}

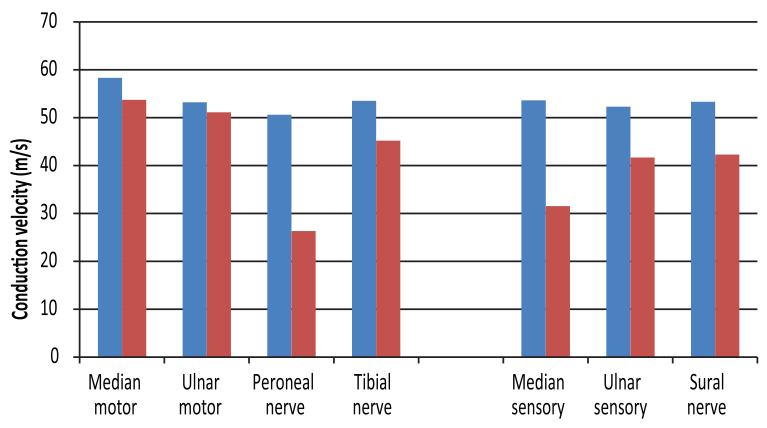

Figure 1. Bar diagram showing conduction velocity of motor and sensory nerves of upper and lower limbs

\section{Discussion}

The cause of DPN though remains unknown but ischaemic and metabolic components are implicated. Hyperglycaemia induces rheological changes, which increases endothelial vascular resistance and reduces nerve blood flow. Hyperglycaemia also causes depletion of nerve myoinositol through a competitive uptake mechanism. Moreover, activation of polyol pathway in the nerve through enzyme aldose reductase leads to accumulation of sorbitol and fructose in the nerve and induces nonenzymatic glycosylation of structural nerve proteins. Hyperglycaemia also induces oxidative stress. Activation of protein kinase $\mathrm{C}$ has been linked to vascular damage in $\mathrm{DN}$. These changes result in abnormal neuronal, axonal, and Schwann cell metabolism, which result in impaired axonal transport. Endoneural hypoxia is produced by increased vascular resistance and reduced blood flow in the nerve. Hypoxia leads to further capillary damage, which in turn aggravates disturbance in axonal transport and reduced $\mathrm{Na}-\mathrm{K}$ ATPase activity leading to axonal atrophy and impairment of nerve conduction ${ }^{6}$.

This study describes nerve conduction study parameters in diabetic patients with and without clinical features of DPN. Our study demonstrates that DPN is characterized by slowed motor and sensory conduction velocity with lowered distal and proximal motor amplitudes in both the lower limb and upper limb nerves. The nerve conduction results in DPN are consistent with a sensorimotor polyneuropathy involving the lower extremities more than the upper extremities and with conduction slowing greater than that usually attributed to axonal-loss lesions. ${ }^{9}$ Misra and Kalita in their patients

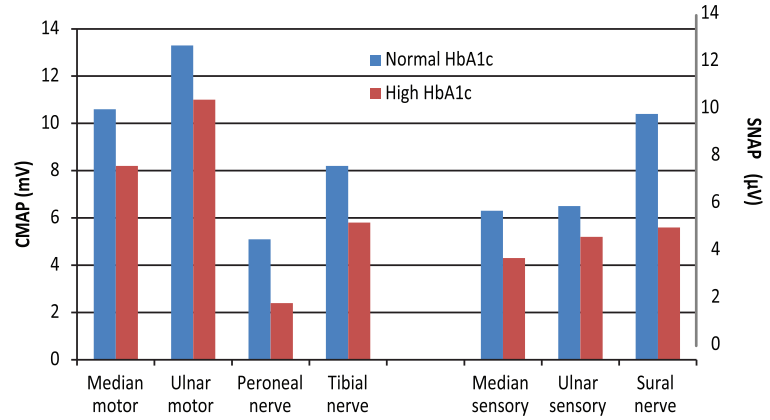

Figure 2. Bar diagram showing amplitude of motor and sensory nerves of upper and lower limbs.

with diabetic neuropathy ${ }^{6}$ obtained results similar to the present study: they found that NCS revealed reduced CMAP and/or SNAP amplitudes, slowing of motor and sensory nerve conduction velocity on proximal stimulation. Similar to our patients, reduction of amplitudes was shown to be more marked in lower limb nerves. In general, nerve conduction declined in all nerves tested, with the decline in sural sensory conduction velocity achieving statistical significance ${ }^{10}$. Sensory nerve action potential amplitude is reduced by up to $60 \%$ in the legs ${ }^{11}$.

Sensory NCS are more sensitive in identifying mild abnormalities than are motor studies, and the most common and most severe abnormality is a reduction in SNAP amplitudes, particularly in the legs. The extent of abnormality on NCS is related to the severity of neuropathy ${ }^{11}$. In another study, motor NCV in the median and peroneal nerves was significantly slowed and lowered CMAP amplitudes as compared to normals. Similarly, SNAP amplitudes were significantly reduced, and sensory NCV was slowed. The decrease in amplitude does not necessarily indicate a loss of sensory fibres, in that slowing can account for a decrease in amplitude. Up to a $50 \%$ decrease in the sensory potentials and increased temporal dispersion can be accounted for solely by the slowing in conduction without requiring the assumption of loss of fibres, consistent with findings of more or less advanced segmental demyelination and remyelination as the predominant histological abnormality ${ }^{12}$. Thus DPN is a continuous process, progressing over time. The electrophysiological features of DPN also show a progression in the manner outlined above. This is attributable to the fact that DPN is a length-dependent 
process similar to other metabolic or toxic neuropathies: thus, at the time of our cross-sectional electrophysiological evaluation more severe changes would be evident in the lower limbs than the upper limbs. In other words, the lower limb nerves would exhibit the later features (i.e. axonal loss) of DPN.

Neuropathy can occur early in the course of diabetes, even before development of other evidences of disturbance in carbohydrate metabolism. In many patients symptoms or signs of neuropathy appear before or about at the time when the metabolic disturbance was diagnosed. The diabetic neuropathy may then be a direct consequence or an integral part of the metabolic defect, and even the finding of greater slowing in motor conduction when the diabetes had lasted for more than five years does not invalidate this idea. It may merely reflect the increased probability of finding more severe manifestations of a neuropathy when the diabetes has lasted longer ${ }^{9}$. This interpretation is in keeping with the absence of a relation between the clinical duration of the diabetes and the impairment in motor conduction and other electrophysiological abnormalities in the individual patient, as is seen in the present study where duration of diabetes did not affect the NCS parameters significantly.

Non-enzymatic glycosylation of haemoglobin occurs in the setting of raised blood glucose levels, and the $\mathrm{HbA} 1 \mathrm{c}$ level is a measure of glycaemic control over the previous 12-14 weeks. As DPN is related to chronic hyperglycaemia, poorer long-term glycaemic control contributed to worsening neuropathy. ${ }^{13}$ The risk of developing DPN has been calculated to rise by approximately $10-15 \%$ for every $1 \%$ rise in $\mathrm{HbA} 1 \mathrm{c} .{ }^{13}$ $\mathrm{HbA1c}$ levels (but neither fasting nor postprandial glucose levels) showed a strong correlation with changes in motor and sensory NCS parameters: the higher the level, the more pronounced the changes on motor and sensory NCS. In an earlier study too, no positive correlation between blood glucose levels and alterations in NCS parameters was found. ${ }^{14}$ Some studies have shown the abnormalities to be more prominent with longer duration of diabetes, whereas others have not. The severity of nerve-conduction abnormalities positively correlated with the severity of hyperglycemia, and is also reported to parallel the duration of diabetes or metabolic control in some studies. However, other studies do not find such correlation.
High $\mathrm{HbA1c}$ levels were associated with lowered CMAP amplitudes in the peroneal and sural in lower limbs and median sensory and ulnar sensory nerves in upper limbs. Slowing of motor NCV was associated with high $\mathrm{HbA1}$ c levels in both upper and lower limb nerves. This change in motor and NCS parameters with reference to their relationship to $\mathrm{HbA} 1 \mathrm{c}$ levels again suggests that chronic hyperglycaemia rather than dayto-day elevations in blood sugar levels is associated with worsening of both the clinical and the electrophysiological features of distal symmetric polyneuropathy.

Since sural sensory abnormalities are the earliest findings in distal symmetric polyneuropathy, the sural NCS findings in this cross-sectional study may represent a later stage of nerve damage independent of the blood sugar levels. Patients with poorer glycemic control or milder neuropathy tended to show greater changes after treatment. The authors concluded that glycaemic control alters the speed of nerve conduction relatively quickly ${ }^{15}$. A simple rule is that a $1 \%$ fall in $\mathrm{Hb} 1 \mathrm{Ac}$ improves the conduction velocity by about $1.3 \mathrm{~m} / \mathrm{s}$ within that time frame ${ }^{6}$. The present study provides further support that blood glucose level, over time, significantly affects NCS parameters.

\section{Conclusion}

The physiological properties of nerve and muscle are modified due to pathophysiological changes resulting from DM. Diabetic patients had lowered motor and sensory potential amplitudes and slowed motor and sensory conduction velocity, affecting motor nerves in lower limbs \& sensory nerves in both upper and lower limbs. High $\mathrm{HbA} 1 \mathrm{c}$ levels were related to axonal and demyelinating changes in both upper and lower limbs. The present study supports that blood glucose level, over time, significantly affects NCS parameters. By regular NCS and good glycaemic control, symptoms of DN can be improved and complications can be prevented.

Conflict of interest: No conflict of inertest.

Declaration: This paper was presented in the Conference of Society of Neurologists of Bangladesh, Dhaka, 2016.

\section{References}

1. Boulton AJM, Malik RA, Arezzo J, Sosenko JM: Diabetic neuropathy: technical review. Diabetes Care. 2000; 27 : 1458-87. 
2. Reiber GE, Vileikyte L, Lavery L, Boyko EJ, Boulton AJM. Causal pathways for incident lower-extremity ulcers in patients with diabetes from two settings. Diabetes Care. 1999; 22: $157-62$.

3. Pecoraro RE, Reiber GE, Burgess EM. Pathways to diabetic limb amputation: basis for prevention. Diabetes Care 1990; 13: $513-21$.

4. Rathman W, Ward J. Socioeconomic aspects. In: Gries FA, Textbook of Diabetic Neuropathy. Cameron NE, Low PA, Ziegler D, Eds. Stuttgart, Thieme, 2003, p. 361-372.

5. Vileikyte L: Psychological aspects of diabetic peripheral neuropathy. Diabetes Rev 1999; 7: 387-94.

6. Bansal V, Kalita J, Misra UK, Diabetic neuropathy. Postgraduate Medical Journal 2006; 82, 95-100.

7. Tesfaye S, Boulton AJM, Dyck PJ, Freeman R, Horowitz $\mathrm{M}$, Peter Kempler, et al and on behalf of the Toronto Diabetic Neuropathy Expert Group Diabetic Neuropathies: Update on Definitions, Diagnostic Criteria, Estimation of Severity, and Treatments. Diabetes Care 2010 Oct; 33(10): 2285-2293.

8. Vinik AI. Advances in diabetes for the millennium: new treatments for diabetic neuropathies. Med Gen Med 2004; 17;6(3 Suppl):13.

9. Albers JW, Brown MB, Sima AAF, Green DA. Nerve conduction measures in mild diabetic neuropathy in the Early Diabetes Intervention Trial: The effects of age, sex, type of diabetes, disease duration, and anthropometric factors. Neurology 1996; 85-91.

10. Brown MJ, Bird SJ, Watling S, Kaleta H, Hayes L, Eckert S et al. Naturalprogression of diabetic peripheral neuropathy in the zenarestat study population. Diabetes Care 2004; 27 : 1153-59.

11. Rendell MS, Katims JJ, Richter R, Rowland F. A comparison of nerve conduction velocities and current perception thresholds as correlates of clinical severity of diabetic sensory neuropathy. Journal of Neurology, Neurosurgery, and Psychiatry 1989; 52: 502-11.

12. Lamontagne A, \& Buchthal F. Electrophysiological studies in diabetic neuropathy. Journal of Neurology, Neurosurgery, and Psychiatry 1970; 33; 442-52.

13. Mythili A, Kumar D, Subrahmanyam K, Venkateswarlu KAV, Butchi RG. A comparative study of examination scores and quantitative sensory testing in diagnosis of diabetic polyneuropathy. International Journal of Diabetes in Developing Countries 2010; 30: 43-48.

14. Trujillo-Hernández, B, Huerta $\mathrm{M}$, Trujillo X, Vásquez C , Pérez-Vargas D, \& Millán-Guerrero, R. O. F-wave and Hreflex alterations in recently diagnosed diabetic patients. Journal of Clinical Neuroscience 2005; 12: 763-66.

15. Kikkawa Y., Kuwabara, S. Misawa, S. Tamura, N. Kitano, Y. Ogawara, K. et al. The acute effects of glycemic control on nerve conduction in human diabetics. Clinical Neurophysiology 2005; 116; 270-74. 